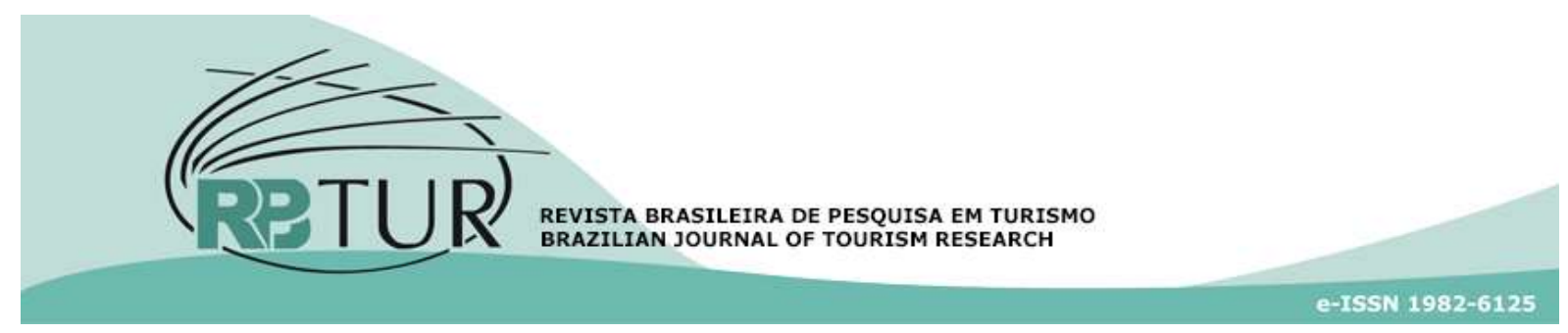

Artigo

DOI: http://dx.doi.org/10.7784/rbtur.v12i1.1368

\title{
Experiências memoráveis de viagens de casais
}

\author{
Memorable Experience of Couples' Trips
}

\section{Experiencias Memorables de Viajes de Parejas}

\author{
Mariana de Freitas Coelho ${ }^{1}$ \\ Kelly Cristine de Oliveira Meira ${ }^{2}$ \\ Marlusa de Sevilha Gosling ${ }^{3}$
}

Resumo: A experiência turística é um termo que se associa a múltiplas interpretações que permeiam o ambiente, as pessoas e outros componentes da atividade. O objetivo deste artigo é identificar a essência de viagens memoráveis de casais a lazer, tendo em vista que a viagem a dois ainda é pouco estudada. Entende-se "casais" como um termo amplo, formado por indivíduos que possuem relação sentimental e/ou sexual, como casais de namorados, pessoas legalmente casadas (cônjuges), público GLBT e indivíduos de diferentes idades e estilos de vida. O método do trabalho é qualitativo e exploratório, sendo composto por três estudos distintos e complementares. $\mathrm{O}$ primeiro estudo envolveu relatos de dois casais durante a experiência de viagem dos mesmos. $\mathrm{O}$ segundo estudo é composto por narrativas de viagem a dois por uma das partes do casal, com roteiro semiestruturado. $O$ terceiro estudo abarcou entrevistas em profundidade com casais que possuíam acima de 18 anos e viajaram a lazer pelo menos uma vez nos 12 meses anteriores à data da coleta de dados. A análise dos dados se deu via análise de conteúdo do texto, por meio da categorização temática. Os resultados demonstram que a viagem a dois proporciona a criação de eventos memoráveis, em que estórias e situações vividas podem ser compartilhadas posteriormente entre o casal e seus conhecidos. Além da fuga da rotina, diversão e relaxamento, as datas comemorativas e as paixões em comum também são motivadores para viagens do casal. Assim, organizações de destino turístico devem identificar interesse em comum do casal para melhor atendê-los. As contribuições do estudo remetem à abordagem da experiência em grupo ao invés da perspectiva individual.

\footnotetext{
${ }^{1}$ Faculdade Batista de Minas Gerais, Belo Horizonte, MG. É a idealizadora do trabalho, tendo feito parte de sua pesquisa de doutorado. Contribuiu para pesquisa, escrita e toda ação relacionada à submissão do trabalho. Conduziu o estudo 1.

${ }^{2}$ Universidade Federal de Minas Gerais, Belo Horizonte, MG. Atuou como bolsista do projeto, contribuindo para a busca de bibliografia, redação e formatação do artigo e busca de participantes para a pesquisa. Conduziu o estudo 3.

${ }^{3}$ Universidade Federal de Minas Gerais, Belo Horizonte, MG.Contribuiu para a visão crítica e aperfeiçoamento do artigo. Prestou orientações metodológicas e do design do artigo, revisou o instrumento de pesquisa e apoiou a coleta de dados. Conduziu o estudo 2.
}

Artigo recebido em: 28/09/2017. Artigo aceito em: 08/02/2018. 
Palavras-chave: Experiências Turísticas Memoráveis. Viagens de casais. Relacionamentos interpessoais.

Abstract: The tourism experience is a term which is associated with multiple interpretations that permeate the environment, people and other components of the activity. The objective of this article is to identify the essence of memorable leisure trips of couples, considering that the trip of couples is still little studied. "Couples" is understood as a broad term, consisting of individuals who have a romantic and/ or sexual relationship, such as lovers, legally married persons (spouses), GLBT public, and individuals of different ages and lifestyles. The work method is qualitative and exploratory, composed of three different and complementary studies. The first study included stories of two couples during their travel experience. The second study is composed of narratives of couple trips described by one of the parts of the pair, with semi structured script. The third study covered indepth interviews with couples who were older than 18 years and traveled for leisure at least once in the 12 months prior to the date of data collection. The data analysis was done through content analysis, through thematic categorization of the text. The results show that the couple trip provides the creation of memorable events, in which the stories and situations lived can be shared later between the couple and their acquaintances. In addition to routine escape, fun and relaxation, commemorative dates and passions in common are also motivating for the couple's travels. Thus, tourism destination organizations should identify common interest of the couple to better serve them. The contributions of the study refer to the group experience approach rather than the individual perspective.

Keywords: Memorable Tourism Experience. Couple trips. Interpersonal Relationships.

Resumen: La experiencia turística es un término que se asocia a múltiples interpretaciones que permean el ambiente, las personas y otros componentes de la actividad. El objetivo de este artículo es comprender las particularidades de viajes memorables de parejas, teniendo en cuenta que el viaje a dos todavía es poco estudiado. Se entiende "parejas" como un término amplio, formado por individuos que poseen relación sentimental y / o sexual, como parejas de novios, personas legalmente casadas (cónyuges), público GLBT y individuos de diferentes edades y estilos de vida. El método del trabajo es cualitativo y exploratorio, compuesto por tres estudios distintos y complementarios. El primer estudio incluyó relatos de dos parejas durante la experiencia de viaje de los mismos. El segundo estudio es compuesto por narrativas de viaje a dos por una de las partes de la pareja, con guión semiestructurado. El tercer estudio abarcó entrevistas en profundidad con parejas mayores de 18 años y que viajaron por ocio al menos una vez en los 12 meses anteriores a la fecha de la recolección de datos. El análisis de los datos se dio a través del análisis de contenido del texto, por medio de la categorización temática. Los resultados demuestran que el viaje a dos proporciona la creación de eventos memorables, en que las historias y situaciones vividas pueden ser compartidas posteriormente entre la pareja y sus conocidos. Además de la fuga de la rutina, la diversión y la relajación, las fechas conmemorativas y las pasiones en común también son motivadores para los viajes de la pareja. Así, organizaciones de destino turístico deben identificar interés en común de la pareja para mejor atenderlos. Las contribuciones del estudio se refieren al enfoque de la experiencia en grupo en lugar de la perspectiva individual.

Palabras clave: Experiencias Turísticas memorables. Viajes de parejas. Relaciones interpersonales.

\section{INTRODUÇÃO}

Alguns estudos apontam que a literatura de marketing reforça a necessidade de se estudar os consumidores em uma perspectiva grupal ao invés da individual (Lawson, 2010). É particularmente a perspectiva da abordagem da experiência em grupo, especificamente, a experiência turística de casais, que é foco dessa pesquisa.

A justificativa social desse trabalho envolve uma percepção ampla sobre o conceito de casais. De acordo com o Dicionário 
Aurélio $^{4}$ (s.d.), um casal pode ser definido como: "1. Par formado por macho e fêmea. 2. Par formado pelo cônjuge. 3. Conjunto de duas pessoas que têm uma relação sentimental e/ou sexual. (...)". Apresentada a terceira definição, esse artigo se apropria do termo casais em suas mais variadas formas, inclusive, casais de namorados, pessoas legalmente casadas (cônjuges), público GLBT e indivíduos de diferentes idades e estilos de vida. Com isso, pretende-se entender as experiências de viagens de casais dentro de uma abordagem inclusiva.

Sobre os hábitos dos brasileiros que costumam viajar, $21,6 \%$ viaja com o cônjuge, ficando atrás apenas de viagens em família, isto é, cônjuge e filhos, que somam 29,1\% (Brasil, 2009). Apesar da relevância de se estudarem as peculiaridades de viagens de casais, pesquisas sobre experiências de viagens desse grupo específico ainda são escassas no Brasil (Gama \& Siqueira, 2010). Conforme Lawson (2010), poucas pesquisas presentes no Journal of Consumer Research mencionam um grupo demográfico específico como fonte de interesse de estudo, sendo que a maioria se concentra em uma faixa etária determinada, com mais estudos sobre crianças e adolescentes do que idosos. Desse modo, identifica-se uma lacuna para estudos que incluam grupos de indivíduos, ao invés de pesquisas em perspectivas individuais. Dentre os grupos de indivíduos que podem ser pesquisados no contexto turístico estão os idosos, casais e pessoas inseridas em diferentes estágios no ciclo de vida familiar.
Diante do exposto, a pergunta que norteia esse trabalho é: Qual a essência da experiência de casais de brasileiros que viajam a lazer? O objetivo é identificar a essência de viagens memoráveis de casais, a lazer. Dentre as contribuições desse estudo, temse o apontamento de temas e categorias que envolvem a viagem a dois, por meio da apresentação de um framework teórico. Ademais, inova-se ao investigar a experiência de viagens abarcando o casal como objeto de estudo. Em outras palavras, ao trabalhar a experiência do casal em conjunto, o estudo se distingue da perspectiva individual a qual é dominante nos estudos sobre o tema.

\section{MARCO TEÓRICO}

\subsection{Experiências Turísticas Memoráveis}

A experiência turística é um termo construído socialmente e se associa a múltiplas interpretações que permeiam o ambiente, o social e outros componentes da atividade (Tussyadiah \& Fesenmaier, 2009). A experiência memorável também cria vínculo emocional com o local visitado (Song et al.,2014).

Contudo, nem toda experiência turística é capaz de gerar lembranças memoráveis. Uma experiência memorável diz respeito ao sentimento de estar presente em um lugar, sentindo, vivenciando e absorvendo aquele momento específico. $O$ que torna uma experiência inesquecível é, principalmente, compartilhá-la com as pessoas ou

\footnotetext{
${ }^{4}$ Disponivel em < http://www.dicionariodoaurelio.com/casal>. Acesso em 26/05/2017
} 
criar laços durante a experiência, o que reforça o papel das emoções como o ponto central das experiências memoráveis (Knobloch, Robertson, \& Aitken, 2014).

Há autores que demonstram a importância do relacionamento interpessoal para a memorabilidade da experiência, bem como seus outputs. Segundo Cohen (1979), a experiência turística é a relação entre pessoas e sua visão de mundo, dependendo da sociedade a qual o indivíduo pertence. Portanto, o componente pessoal é central para a entrega de experiências (Bharwani \& Jauhari, 2013). Schmitt (2000) considera que um dos provedores de experiência é o contato ou a observação de outros indivíduos. Para Tussyadiah e Fesenmaier (2009), o engajamento entre pessoas geralmente funciona como mediador da experiência turística, permitindo a interpretação, compartilhamento e ressignificação de momentos da viagem. As interações face a face provocam sentimentos fortes, destacando, assim, a relação entre os sentimentos e os encontros pessoais (Schmitt, 2000). Além disso, visitantes que interagem com a cultura local constroem uma experiência de viagem única e memorável (Kim \& Ritchie, 2014).

Como o principal objetivo da atividade turística é entregar experiências, os prestadores de serviços turísticos precisam proporcionar experiências funcionais e emocionais que sejam positivas para que os consumidores se sintam satisfeitos (Song, Lee, Park, Hwang, \& Reisinger, 2014; Knobloch et al., 2014). Isso se dá especialmente porque as lembranças das experiências de viagem são motivadores para que o turista revisite o local e também o recomende (Tung \& Ritchie, 2011).

Há também diversos estudos demonstram as múltiplas dimensões da experiência turística e sua relação com a satisfação do consumidor. Oh, Fiore e Jeoung (2007) e Song et al. (2014) usaram a teoria dos quatro domínios da experiência - 4E's (Escapismo, Educação, Estética, Entretenimento) - de Pine e Gilmore (1999) como ponto de partida para estudar a satisfação dos turistas com as experiências em estabelecimentos de Cama \& Café (B\&B) e em templos, respectivamente. Oh et al. (2007) encontraram que a dimensão estética é o principal aspecto na determinação da satisfação dos clientes enquanto os aspectos entretenimento e escapismo não eram significantes, contrastando com os achados do estudo de Song et al. (2014). No estudo de Song et al. (2014), o escapismo, o entretenimento e a educação afetam o valor funcional e o escapismo, o entretenimento e a estética afetam o valor emocional, na determinação da satisfação do visitante.

Os resultados desses estudos demonstram que os quatro níveis da experiência de Pine e Gilmore (1999) precisam ser adaptados pela empresa ou destino turístico de acordo com o serviço e/ou atividade a ser oferecida. Isso leva ao objetivo de proporcionar ao turista uma experiência memorável que o satisfará e, consequentemente conduz a revisita e a recomendação da mesma (Oh et al., 2007; Song et al., 2014; Tung \& Ritchie, 2011).

Percebe-se pela literatura que o desenvolvimento de relacionamentos interpes 
soais, aspectos estéticos e ambientais, bem como culturais estão entre os principais pontos que uma experiência memorável deve proporcionar ao consumidor. Todavia, é necessário ressaltar a improbabilidade de que duas pessoas vivenciem a mesma experiência ou emoções, ainda que participem das mesmas atividades ou desfrutem os mesmos serviços (Tung \& Ritchie, 2011; Knobloch et al., 2014). Assim, pretende-se aprofundar no entendimento das relações interpessoais como criadora de memórias marcantes de uma experiência turística.

\subsection{Relações Interpessoais}

Ao se perguntar quais seriam os recursos humanos para as organizações turísticas e para a experiência turística de qualidade, Beni (2004) considera que a chave da experiência está nesse processo interativo, no qual moradores, visitantes e turistas decodificam o diferencial do patrimônio natural e cultural. "Faz-se necessário então, pela pesquisa e interpretação do diferencial turístico, estimular a atenção, o 'olhar', o sentimento, a emoção, as sensações e percepções para que o turista possa experienciar o antes até então ignorado." (Beni, 2004, p. 296).

Sabe-se que os estudos turísticos devem, dentre outros aspectos, ampliar o conhecimento sobre o lazer, o imaginário e as relações interpessoais entre diferentes culturas (Beni, 2004). A interação interpessoal pode ser positiva ou negativa e é altamente recomendada em serviços complexos como no turismo, dependendo das interações facea-face para a geração de sentimentos (Schmitt, 2000). Trigo (2010, p. 31) também associa a viagem a pessoas. Para o autor, "uma viagem especial exige pessoas e condições especiais. Isso não implica apenas poder econômico, mas fundamentalmente atitudes e posturas sociais, culturais, estéticas e políticas".

Uma vez que a orientação cultural entre prestadores de serviço e o cliente pode ser muito distinta, pessoas que tem contato com o turista devem ser sensíveis aos valores e expectativas de consumidores globais (Bharwani \& Jauhari, 2013). Estratégias bem sucedidas criam vínculo emocional com o estilo de vida do consumidor por meio da confiança, da entrega dos produtos/serviços e da sustentabilidade (Hannam, 2004). Ou seja, o grau de empatia e proximidade culturais compartilhados entre viajantes e empregados influenciam na entrega da experiência ao turista. Um funcionário pode encenar suas tarefas melhor se possuir habilidades de inteligência emocional como inteligência interpessoal (capacidade de relacionamento com outros) e intrapessoal (resiliência, otimismo, comprometimento) (Bharwani \& Jauhari, 2013).

Por conseguinte, vários autores já destacaram a importância das pessoas para a experiência turística (Carù \& Cova, 2003; Komppula, Ilves \& Airey, 2016; Quinlan-Cutler \& Carmichael, 2010; Walls, 2013), mas não se sabe ao certo o peso da presença e/ou da falta de contato interpessoal para a memorabilidade de uma viagem. Um dos caminhos acadêmicos é o estudo da relevância das relações interpessoais para a experiência vivida. Estudar as relações entre turista e agente que fornece serviços/produtos, por exemplo, pode levar a experiências marcantes positivas ou negativas. Portanto, é mister que se entenda a importância da dimensão 
interpessoal para o desdobramento em ações que permitam momentos inesquecíveis aos turistas.

\section{METODOLOGIA}

Visando responder ao problema de pesquisa e atingir aos objetivos propostos, esta pesquisa foi qualitativa e exploratória. Assim, a condução da pesquisa se desdobrou em três estudos com procedimentos e ferramentas distintas. Dado que a experiência de viagem memorável é um fenômeno multifacetado, julgou-se necessário uma aproximação do mesmo para melhor entendimento do campo de estudo. Com isso, a pesquisa contou com três etapas metodológicas distintas.

O primeiro estudo foi composto por dois relatos de viagens de casais que viajaram com seu parceiro (a) e que foram escoIhidos por acessibilidade e por concordaram em participar do estudo. Essa etapa envolveu a divulgação da pesquisa em busca de voluntários em uma rede social (Facebook) de uma das autoras. A intenção foi buscar casais que tivessem a intenção de viajar a dois e "acompanhar a viagem em tempo real", isto é, entender como se dava o processo de vivência, decisão e consumo do casal. A escolha dos sujeitos é justificada por se tratarem de casais fora do padrão, isto é, casais que estavam em situações que fogem do tradicional e rotineiro. Logo, o primeiro casal é formado por noivos, de nacionalidades distintas, residentes no exterior, que viaja com interesse de montar um negócio próprio. Já o segundo casal mora em cidades diferentes, ambos brasileiros, namorados, em processo de irem morar juntos.

Apesar de nenhum tipo de roteiro estruturado ter sido utilizado como instrumento, os casais receberam orientações sobre quais informações eram de interesse dos pesquisadores, a frequência de envio dos relatos e demais informações pertinentes. Estimulou-se o envio de: imagens; relatos de visitas a atrativos turísticos; experiências de contato com serviços (hospedagem, alimentação, passeios); e contato com moradores ou turistas. Com isso, o primeiro estudo permitiu uma melhor compreensão das sensações, descobertas, fontes de satisfação e insatisfação com os destinos durante a experiência de viagem. Outros aspectos como relacionamento com prestadores de serviços e experiências positivas e negativas vividas no local também foram descritos pelos participantes.

A narrativa foi utilizada para a coleta dos dados no primeiro e no segundo estudo, porque contribui para a compreensão das experiências narradas que envolvem relatos de cenários específicos (Riessman, 2005). Conforme Matos, Branco e Barradas (2005) a narrativa é uma abordagem rica para investigações de experiência humana e interação entre as pessoas, que são, justamente os dois enfoques deste estudo. Arnould e Price (1993), Uriely (2005) e Pearce e Wu (2014), dentre vários outros estudos de experiência turística, também utilizaram da narrativa de viajantes para a compreensão da experiência de viagem, o que demonstra se tratar de uma técnica de coleta de dados comumente utilizada nesta conjuntura.

O segundo estudo envolveu a seleção 
de viajantes brasileiros que já passaram por experiências de viagens memoráveis. Os participantes eram alunos de um curso de graduação em Administração de uma universidade federal brasileira. Os participantes foram convidados a escrever sobre suas experiências turísticas que foram feitas com uma ou mais pessoas por meio de um texto narrativo. Ao todo, 22 indivíduos escreveram narrativas pautadas em um roteiro semiestruturado. Desse total, 9 textos foram excluídos do estudo por narrar viagens com grupo de amigos ou familiares. Assim, apenas relatos de viagens de casais foram mantidos, totalizando 13 narrativas individuais.

A exemplo do estudo um, o estudo dois também utilizou como método para coleta de dados a narrativa, mas diferente do estudo um onde os casais fizeram os relatos juntos e durante a viagem, os dados do estudo dois são compostos por narrativas feitas pós-viagem por uma das partes do casal. 0 segundo estudo é constituído por 13 narrativas de viagem que foram guiadas por um roteiro semiestruturado (Quadro 1).

Quadro 1 - Roteiro

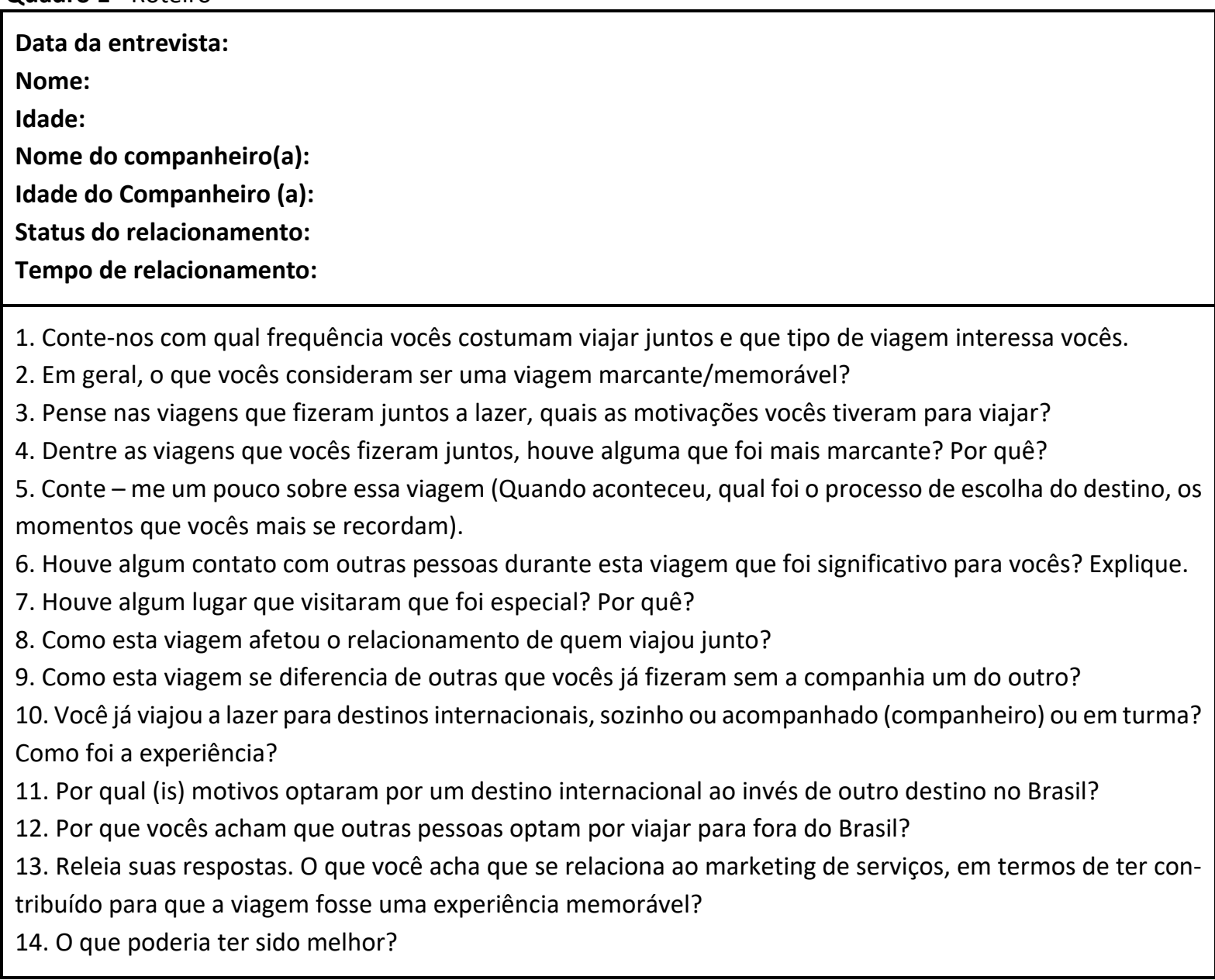

Fonte: Autoria Própria

Tendo em vista a aproximação com o dos, optou-se por avançar em um terceiro esfenômeno alcançado nos dois primeiros estu- tudo sobre as experiências de viagens memo- 
ráveis de casais brasileiros em suas mais diversas formas como namorados, casados, público GLBT de diferentes idades e situações socioeconômicas.

O terceiro estudo foi composto por entrevistas qualitativas em profundidade com casais que viajaram para pelo menos um destino doméstico e/ou um destino internacional, em conjunto e a lazer. $O$ estudo 3 envolveu a técnica bola-de-neve, em que três casais foram selecionados por conveniência iniciar o estudo e eram solicitados a indicar outros casais que poderiam ser entrevistados para dar continuidade à pesquisa. As entrevistas foram conduzidas por casal, totalizando 11 casais ( 22 indivíduos). Como delimitação, o casal deveria ter viajado pelo menos uma vez em um período de até 12 meses antes da fase de coleta de dados e ter idade superior a 18 anos. Assim, foram estudados casais que viajaram recentemente e com poder de decisão sobre a viagem a lazer.

A entrevista em profundidade foi escolhida por atender bem às pesquisas qualitativas com finalidade exploratória e proporcionar detalhamento de questões e formulação de conceitos relacionados. A entrevista em profundidade é, em geral, aplicada individualmente. Contudo, como este trabalho possuiu interesse em entender a experiência de viagens memoráveis de casais, a ideia foi entrevistar o casal em conjunto.

Esta estratégia é pouco utilizada na literatura, principalmente nos estudos de experiências turísticas no Brasil, que não enfatizaram esta unidade de análise. A única exceção foram os estudos de Gama e Siqueira (2010) que propuseram apenas considera- ções teóricas sobre viagens de lua de mel, ou seja, não apresentaram propostas empíricas. Contudo, a entrevista em profundidade com o casal é pertinente visto que os mesmos são tratados com unidade de observação e a técnica permite deixar "o entrevistado o mais livre possível para expressar suas opiniões" (Vieira \& Tibola, 2005, p. 14).

Utilizou-se um roteiro de entrevistas semiestruturado, visando dar flexibilidade ao pesquisador para aprofundar em questões que surgissem durante a entrevista. $O$ roteiro do estudo 2 foi adaptado para as entrevistas do estudo 3 . O critério para a escolha do momento de finalização das entrevistas foi por saturação das respostas (Malhotra, 2004). Portanto, a coleta dos dados se encerrou ao alcançar 11 casais entrevistados.

Para a análise dos dados dos três estudos, foi adotada a análise de conteúdo do texto por meio da categorização temática $a$ posteriori, conforme Bardin (2008). Após a transcrição das entrevistas e relatos, foi feita a leitura flutuante dos textos. Buscou-se comparar as respostas dos casais entrevistados, procurando elementos em comum e também específicos de cada casal. Ainda, além do contraste dos dados com a literatura de experiência turística e os achados nos primeiros dois estudos, foram procurados elementos não listados na literatura.

Além da categorização por temas e posterior síntese em famílias de códigos, entendeu-se que para condensar as principais características de experiências de viagens de casais era necessário propor um framework teórico. Por fim, para aumentar a validade das respostas, utilizou-se o método de valida- 
ção cruzada, em que três pesquisadores avaliaram o conteúdo das narrativas e transcrições das entrevistas.

\section{RESULTADOS}

Os resultados são apresentados por estudo, grifando em negrito as principais categorias temáticas que apareceram nos resultados de cada estudo. Apresenta-se a discussão de maneira conjunta (todos os 3 estudos) após os resultados, juntamente com a síntese temática e framework teórico resultante dos estudos.

\subsection{Estudo 1 - Relatos de Viagem}

O estudo 1 é fruto de dois relatos de viagem de casais que foram escolhidos por se tratarem de casais em situações distintas de muitos casais existentes. Ou seja, ambos são casais que passam por situações atípicas, se comparadas com os demais casais.

O primeiro casal é formado por noivos, sendo uma mulher brasileira, comissária de bordo, e um libanês. O casal se conheceu em Dubai em 2015 e convive diariamente com as diferenças culturais, religiosas, linguísticas e gastronômicas. Atualmente, estão montando um micro negócio de viagens pelo Líbano, para atender às demandas dos comissários de bordo que viajam para o país, o Lebanon Road Trips, assim, um dos objetivos da viagem do casal é adquirir conhecimento e alimentar a página do Facebook do negócio. O relato de viagem do casal aborda uma viagem para as montanhas libanesas na temporada de inverno, ou seja, um ambiente propício para a prática de esportes como snowboard e ski e também uma oportunidade para o casal apreciar a culinária libanesa.
O segundo casal é formado por namorados, brasileiros, uma turismóloga e um professor, apaixonados por história do Brasil, música, gastronomia, cultura, artes e arquitetura. O casal, na época da viagem estava passando por momento distinto no relacionamento, no qual iriam começar a morar juntos. A viagem relatada pelo casal ocorreu durante 12 dias nos quais visitaram as cidades históricas de Vassouras, Barra do Piraí, Valença, Visconde de Mauá, Penedo, Teresópolis e Petrópolis, todas no estado do Rio de Janeiro.

Os achados do estudo 1 demonstraram que ambos os casais possuem diversas paixões em comum e as viagens juntos permitem o compartilhamento dessas experiências entre o casal. O relacionamento interpessoal também pode se dar entre o casal e outras pessoas que eles encontram ao longo da viagem, reforçando os resultados de Beni (2004), segundo o qual a chave da experiência turística é a interação entre os turistas e moradores. $O$ trecho a seguir destaca este inter-relacionamento:

\footnotetext{
“O sr. Patrício é um colecionador de antiguidades apaixonado pela história do Brasil, assim como Arlindo e eu. Fomos embora apenas por educação, pois a vontade era de ficar lá por mais algum tempo." Amélia
}

\section{As novidades vivenciadas e compar-}

tilhadas pelo casal durante a viagem proporcionam maior aproximação entre o casal. Entre as principais novidades compartilhadas pelos casais está a gastronomia, a oportunidade de experimentar alimentos e/ou pratos locais que ainda não são conhecidos. Kim (2010) aponta que o envolvimento com a cultura local e as experiências turísticas aumen- 
ta a capacidade de lembrança das experiências passadas.

Sempre pedimos pratos um do outro, assim podemos provar dois sabores. Amélia

Figura 1 - Banquete Russo

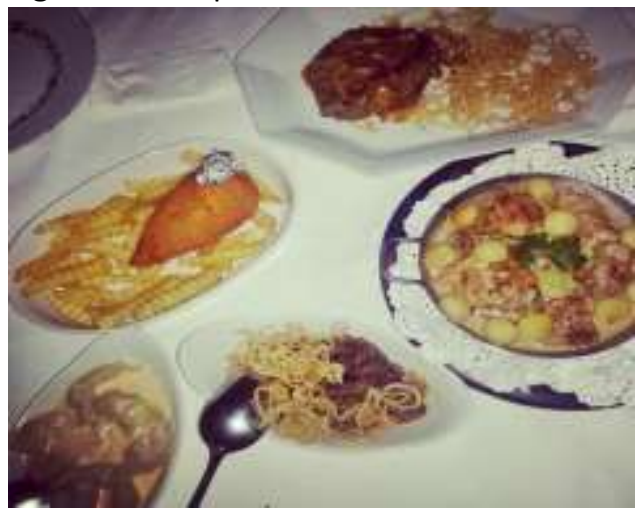

Jantar do casal 2, Amélia e Arlindo

Outra importante situação compartilhada pelos casais foi a novidade ou experiência inédita, isto é, viajar para lugares que o casal não conhecia ou que apenas um deles conhecia. Em ambos os casos houve o compartilhamento de vivências, emoções e de novas experiências, corroborando o estudo de Campos, Mendes, Valle e Scott (2016) no qual as relações próximas
A escolha por Teresópolis foi em razão do restaurante Dona Irene, que o Arlindo sempre quis ir. Lá é servido um banquete russo com seis etapas. Amélia Descobri hoje a diferença entre manoush e saj (são dois estilos de pizza libanesa). Tereza

Figura 2 - Preparação de Pizzas Libanesas

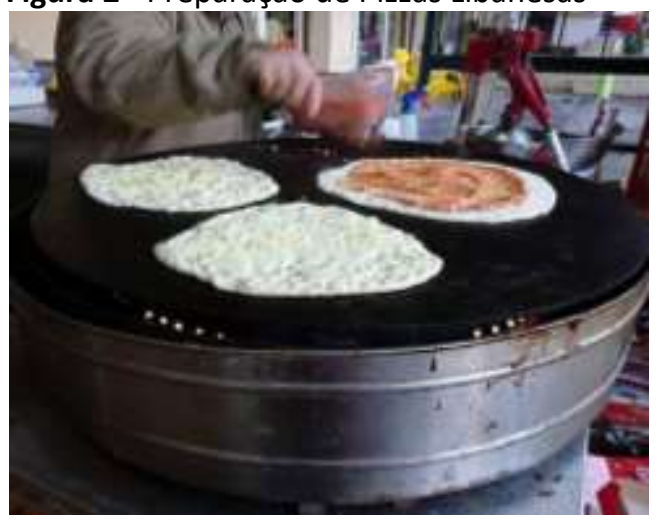

Refeição do casal 1, Tereza e Munir

e intensas, em relação ao afeto, são importantes elementos no contexto da experiência turística.

Achei ótimo, porque eu não conhecia a cidade e o Arlindo achava que eu adoraria. De fato, adorei. Amélia Acabamos fazendo muitas viagens para lugares que nem mesmo ele conhece, então é bem interessante ver a reação dele. Tereza 
Figura 3 - Visita ao Museu Imperial, Petrópolis

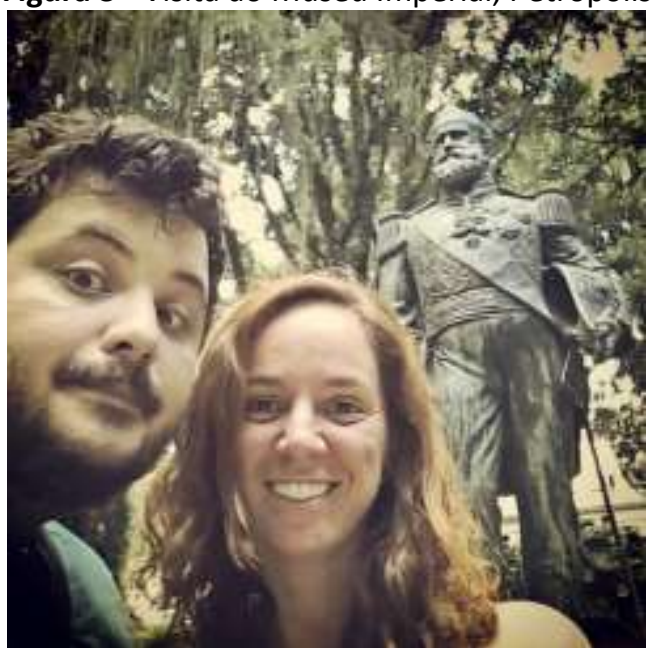

Casal 2, Amélia e Arlindo

O intuito do estudo 1 foi entender o comportamento dos turistas durante as viagens, em tempo real, mas os pesquisadores enfrentaram vários problemas para sua viabilização. Um problema foi a evasão de 6 casais de voluntários que inicialmente participariam da pesquisa. Os motivos foram diversos, como cancelamento da viagem, dificuldade em escrever e dificuldades de comunicação com os pesquisadores por falta de acesso à internet. Com isso, entendeu-se que outras estratégias de pesquisa poderiam contribuir para o entendimento das particularidades das viagens de casais.

\subsection{Estudo 2 - Narrativas}

O estudo 2 é composto de 13 narrativas de viagens que foram feitas por pessoas que viajaram pelo menos uma vez com o(a)
Figura 4 - Montanhas Libanesas

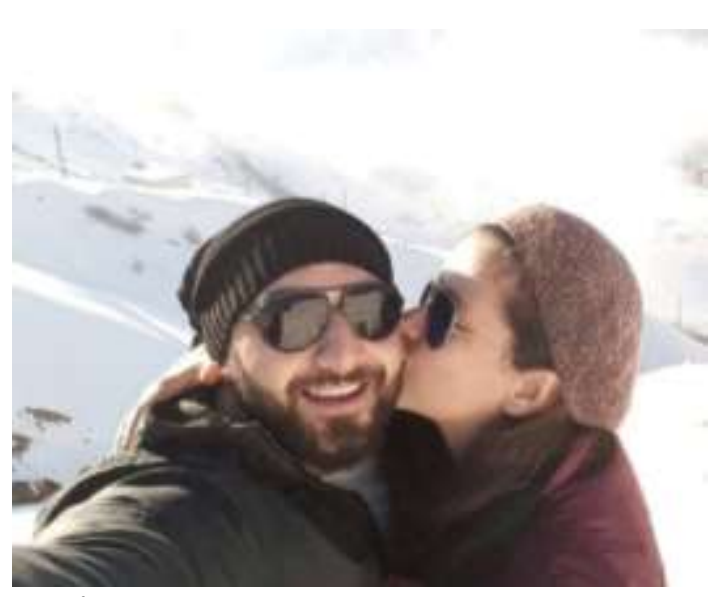

Casal 1, Tereza e Munir

parceiro(a) nos últimos doze meses antes da coleta de dados.

O quadro 2 apresenta a caracterização dos casais e da viagem memorável narrada no estudo 2 . Verifica-se que os casais possuem entre 20 e 30 anos, o que é condizente com o fato de serem estudantes universitários de um curso de graduação. A exceção de dois casais, um que está noivo e outro que terminou o relacionamento, os demais estão namorando. Das 13 narrativas, dois participantes relataram ser homossexuais e os demais heterossexuais. Das 13 narrativas de viagens memoráveis, 5 viagens foram internacionais e 8 nacionais. Sobre o ano da viagem, em geral os relatos descreveram viagens recentes, sendo 2 viagens em 2017, 5 em 2016, 2 em 2015, 1 em 2014, 1 em 2013, e as datas de 2 narrativas de viagens não foram informadas. 
Quadro 2 - Caracterização dos Casais das Narrativas do Estudo 2

\begin{tabular}{|c|c|c|c|c|c|}
\hline Narrativa & Idade (anos) & $\begin{array}{l}\text { Status do Rela- } \\
\text { cionamento }\end{array}$ & $\begin{array}{l}\text { Orientação } \\
\text { Sexual }\end{array}$ & $\begin{array}{l}\text { Tipo de Vi- } \\
\text { agem }\end{array}$ & Data da Viagem \\
\hline N1 & $23-21$ & Namorando & Homo & Internacional & Maio/2016 \\
\hline N2 & $21-21$ & Namorando & Hétero & Nacional & Dez/2016 \\
\hline N3 & $22-22$ & Terminado & Hétero & Nacional & Jan/2016 \\
\hline N4 & ----- & ----- & Hétero & Internacional & Fev/2013 \\
\hline N5 & $21-23$ & Namorando & Hétero & Nacional & ---- \\
\hline N6 & $23-23$ & ----- & Hétero & Nacional & Out/2016 \\
\hline N7 & --26 & Namorando & Hétero & Nacional & Início/2017 \\
\hline N8 & $23-24$ & Namorando & Hétero & Nacional & Fev/2015 \\
\hline N9 & $20-21$ & Namorando & Hétero & Nacional & Fev/2015 \\
\hline N10 & $20-25$ & Noivos & Hétero & Nacional & ----- \\
\hline N11 & $22-25$ & Namorando & Hétero & Internacional & Fev/2016 \\
\hline N12 & ----- & ----- & ----- & Internacional & Dez/2014 \\
\hline N13 & $21-23$ & Namorando & Homo & Internacional & Maio/2016 \\
\hline
\end{tabular}

Fonte: Autoria Própria

Um dos tópicos identificados à posteriori neste estudo envolve as motivações para as viagens de casais. Sobre as motivações de viagens a dois os participantes relataram: a novidade ou experiência inédita em conhecer novos lugares, novas culturas e viverem novas experiências; o descanso para diminuir o stress; sair da rotina e da cidade e estar longe das preocupações; festejar datas comemorativas do casal como aniversário de namoro; a oportunidade de ter tempo livre; preço; a paixão em comum por algum interesse em comum (tipo de turismo, atividade de interesse); aproveitar a companhia do (a) parceiro (a), passar um tempo a sós.
Vontade de conhecer novos lugares ou aproveitar o tempo livre. (N12)

Desejo em comum de viajar e oportunidade de uma folga ou feriado para passar um tempo juntos saindo da rotina. (N7)

Queríamos um lugar diferente para fugir da rotina. (N5)

O relato abaixo corrobora o estudo de Kim (2010), segundo o qual o descanso é valorizado pelos turistas como um benefício psicológico proporcionado pela viagem. Além disso, o sentimento de descanso aumenta a capacidade de recordar as experiências passadas. 
Amamos viajar, procuramos em prol de diminuir stress do dia a dia, aproveitar as férias, vontade de explorar lugares novos. (N13)

Em relação aos motivos pelos quais as pessoas fazem viagens internacionais, os participantes disseram ser: pela falta de infraestrutura para viajar pelo Brasil; o status que uma viagem internacional proporciona; o preço, já que algumas viagens para locais turísticos brasileiros são mais caras que uma viagem internacional; conhecer novas culturas; e a conveniência por estar morando fora do país no momento da viagem. Como pode ser visto, nos trechos abaixo:

O Brasil além de ser caro, muitas vezes não é tão chamativo, pois apresenta problemas com transporte, violência e outros riscos. (N1)

Parte devido à cultura e lugares/arquitetura diferentes, e parte porque viajar para certos destinos internacionais é visto por muitos como símbolo de status. (N11)

Porém, um relato expressou que a viagem internacional também proporcionou uma maior valorização das riquezas nacionais.

O contato com outra cultura faz a gente aprender e expandir os conhecimentos, e até mesmo valorizar aquilo que temos no Brasil. (N3)

Outro tópico identificado no estudo 2 é a interferência da viagem no relacionamento do casal. Dentre as formas que a viagem afetou o relacionamento, os participantes narraram: i) a oficialização do relacionamento durante a viagem; ii) o au- mento da proximidade, pois a viagem permitiu que o casal se tornasse mais unido, mais íntimo, se conhecesse mais e para os casais que moravam em diferentes cidades a viagem foi a oportunidade para matar a saudade; iii) a confiança, já que a viagem deu a certeza de que estavam com o parceiro (a) certo e, iv) a memorabilidade, porque a viagem permitiu o compartilhamento dos momentos de alegria, das experiências e descobertas e, assim, a formação de memórias que os permite dividir recordações entre si e com outras pessoas.

Foi muito positivo, pois nos tornamos ainda mais íntimos. (N4)

O meu relacionamento com a Letícia foi totalmente alterado, já que no início da viagem estávamos "em um relacionamento aberto" e durante a viagem podemos firmar o nosso compromisso de namoro. (N8)

A viagem serviu para nos aproximar ainda mais e reforçar o relacionamento, dar certeza da escolha. (N7)

Entretanto, também houve participantes que relataram que a viagem não afetou o relacionamento.

Não mudou muita coisa. (N2)

Apesar dos elementos encontrados que contribuem para a caracterização da viagem a dois, o método adotado permitiu avaliar apenas a visão de uma das partes do casal. Com isso, fez-se necessário adotar outra estratégia de pesquisa haja vista a necessidade de entendimento do casal como unidade de observação. 


\subsection{Estudo 3 - Entrevistas}

O estudo 3 é fruto de 11 entrevistas em profundidade com casais maiores de 18 anos e que tenham viajado juntos e a lazer nos 12 meses anteriores à coleta dos dados.

O quadro 3 sintetiza as características dos 11 casais entrevistados para o estudo 3. Tem-se casais com idades entre 21 a 38 anos; 8 casais são heterossexuais e 3 são homossexuais; 9 casais são de namorados, 1 casal de noivos e 1 de cônjuges. 0 tempo de relacionamento dos casais varia, sendo o mais recente de 5 meses e o mais longo de 12 anos. Das viagens mais memoráveis descritas pelos casais 7 são internacionais e 4 nacionais. Bem como o estudo 2 , as viagens também são recentes, sendo que 1 viagem ocorreu em 2014, 1 em 2015, 4 em 2016 e 5 em 2017.

Quadro 3 - Caracterização dos Casais das Entrevistas do Estudo 3

\begin{tabular}{|l|l|l|l|l|l|l|}
\hline Casais & $\begin{array}{l}\text { Idade } \\
\text { (anos) }\end{array}$ & $\begin{array}{l}\text { Status do Rela- } \\
\text { cionamento }\end{array}$ & $\begin{array}{l}\text { Tempo de Rela- } \\
\text { cionamento }\end{array}$ & $\begin{array}{l}\text { Orientação } \\
\text { Sexual }\end{array}$ & $\begin{array}{l}\text { Tipo de Vi- } \\
\text { agem }\end{array}$ & $\begin{array}{l}\text { Data da Vi- } \\
\text { agem }\end{array}$ \\
\hline C1 & $22-28$ & Namorando & 1 ano & Hétero & Nacional & Nov/2016 \\
\hline C2 & $22-24$ & Namorando & 1 ano e 2 meses & Hétero & Internacional & Dez/2016 \\
\hline C3 & $22-23$ & Namorando & 1 ano e 9 meses & Hétero & Internacional & Jan/2017 \\
\hline C4 & $29-27$ & Namorando & 1 ano e 2 meses & Homo & Internacional & Março/201 \\
\hline C5 & $26-28$ & Noivos & 2 anos e 4 meses & Hétero & Internacional & Fev/2015 \\
\hline C6 & $21-23$ & Namorando & 5 meses & Homo & Nacional & Fev/2017 \\
\hline C7 & $22-24$ & Namorando & 4 anos & Hétero & Internacional & Jan/2016 \\
\hline C8 & $38-36$ & Casados & 12 anos & Heteros & Internacional & Out/2014 \\
\hline C9 & $24-23$ & Namorando & 1 ano e 6 meses & Hétero & Internacional & Fev/2017 \\
\hline C10 & $25-25$ & Namorando & 1 ano e 6 meses & Homo & Nacional & Jan/2017 \\
\hline C11 & $22-22$ & Namorando & 1 ano e 9 meses & Hétero & Nacional & Julho/2016 \\
\hline
\end{tabular}

Fonte: Elaboração das autoras

Corroborando os achados do estudo 2 sobre as motivações de viagens de casais, os entrevistados do estudo 3 mencionaram: a novidade de conhecer novos lugares, viver novas experiências e fazer algo diferente; o descanso, para fugir da rotina, da cidade e do estresse; a oportunidade de viajar em função de variáveis como tempo livre, preço e a facilidade com o idioma; a paixão em comum, por viagens, pelo time de futebol ou por simulações; e aproveitar a companhia do(a) par- 
ceiro(a), pois a viagem proporcionou um tempo só do casal para ficarem juntos. Finalmente, para os que moram em diferentes cidades, a viagem permite matar as saudades. Os trechos abaixo demonstram algumas dessas motivações.

... a gente tinha vontade de conhecer a cidade e ia ter jogo do Galo lá, a gente já juntou o jogo do Galo e conhecemos a cidade, e rolou uma promoção de voo, a gente pagou barato... (C1)

Fugir do caos de $\mathrm{BH}$, dessa cidade louca e ter experiências novas. (C4)

A questão da língua, também, de compreender, apesar de não falar espanhol dá para compreender. (C8)

... nós gostamos de viajar para conhecer mesmo, para ter diversas experiências, descansar, namorar, ficar um pouco mais juntos e sozinhos em outros lugares e alguma coisa nova. (C5)

... no caso do carnaval a gente decidiu ir pra Brasília pra se ver e ficar juntas... (C6)

Além disso, datas comemorativas como dia dos namorados, aniversário de namoro ou uma época festiva, também é um motivador para viagem de casal.

Foi a data. A gente fez 1 ano de namoro no avião, voltando. (C11)

Os entrevistados também abordaram a possibilidade de visitar o mesmo lugar várias vezes e sempre descobrir algo novo ou viver novas experiências, especialmente se a visita anterior ao local tiver sido feita sem o companheiro(a). Isso se dá porque a viagem a dois, mesmo que para locais conhecidos, permite o compartilhamento de vivências passadas com o par- ceiro (a).

...eu aprendi muita coisa, e aí quando ele foi eu ensinei muita coisa pra ele e também descobri mais coisas. Então, acho que você vai num lugar, você pode ir várias vezes e sempre descobre algo novo. (C2)

Porque eu morei em Berlim, aí eu falei 'quero te mostrar Berlim, a gente vai lá'. (C9)

As motivações para a viagem a dois também são diferentes da viagem sozinho (a), com a família e/ou amigos. O planejamento e os locais frequentados em uma viagem de casal diferem das viagens que são feitas ou grupo ou só. Participantes relataram que a viagem quando é feita sozinho (a) acaba deixando saudade de ter o parceiro (a) ao lado para dividir as experiências.

Pra mim é a diferença está principalmente nas companhias que vem junto nessas viagens, quando viajo sozinha ou com amigos é para lugares mais perto... e quando eu viajo com F. vamos para capitais... a motivação é diferente, o motivo de viajar sozinha é um e o motivo de viajar juntas é outro. Muito diferente. (C6)

... você visita locais diferentes, come em locais diferentes, ou seja, eu não vou em um restaurante 5 estrelas com amigos e não visito um local romântico com amigos. (C5)

As viagens separado não são mais tão legais, sei lá, a gente sente falta e tem que ficar falando 'ah, se você estivesse aqui seria tão melhor, fico imaginando você aqui' ou 'o que você está fazendo?' (C7)

Outro subtema ressaltado no estudo 3 é a memorabilidade, ou seja, os aspectos que tornam a viagem de casal marcante. Entre os aspectos relatados pelos casais, estão: i) datas comemorativas, por 
exemplo, uma viagem para comemorar o aniversário de namoro é mais memorável; ii) o ambiente foi relatado por diversos entrevistados como um aspecto memorável, seja o ambiente físico como o hotel, um restaurante ou um bar, como também a natureza (vulcões, desertos e praias) e o clima do local que fez o casal se sentir bemvindo; iii) a novidade ou experiência inédita, por ter sido a primeira viagem do casal, a primeira viagem internacional, a primeira viagem que o próprio casal pagou, ou ainda, o contato com a cultura, costumes, culinária, povo e lugar diferentes daqueles que o casal normalmente convive; iv) a companhia, o fato da viagem ter sido com o parceiro (a) a torna marcante, as pessoas que encontraram durante a viagem também marcou o casal; v) a expectativa/realização, por ser uma viagem que o casal planejava e sonhava há muito tempo, e, a oficialização do relacionamento que ocorreu durante a viagem ou logo depois da mesma.

... parecia uma realidade alternativa porque a praia fica em uma vila de pescadores onde tem um número $x$ de pessoas que podem ir pra lá acampar e eu nunca tinha acampado. (C10)

Porque Praga tem uma atmosfera meio mágica, eu não sei explicar. (C2)

O que mais marca é se fazemos uma viagem de aniversário de namoro, aí é mais marcante. (C5)

Acho que foi o fato da gente estar programando e sonhando com isso há bastante tempo, era um plano de longa data. (C4)
... eu não me importo com o que vamos fazer teoricamente, eu me importo com companhia. Então se eu estou com ela, eu tô de boa. (C9)

... é porque a gente era só amigos e a partir dessa viagem a gente começou a ficar e depois começou a namorar, então assim eu diria que a viagem deu o pontapé inicial, ainda que a gente não tenha tido nenhum contato físico durante a viagem... (C5)

Foi a primeira vez que a gente teve contato com a neve... foi a primeira vez que a gente viu um vulcão que a gente também não conhecia. Eu acho que foi muito por isso e por ser um país muito organizado e que recebeu a gente muito bem, e acabou que juntou tudo... a gente ficou muito encantado mesmo com o lugar. (C8)

Os resultados do estudo 3 confirmam o que foi encontrado no estudo $2 \mathrm{em}$ relação à interferência da viagem no relacionamento. Os entrevistados afirmaram que a viagem aumentou a proximidade do casal por terem se conhecido melhor e que a viagem foi uma "amostra" do futuro do relacionamento. Ademais, há casos em que a viagem proporcionou a oficialização do relacionamento, já que o casal começou a namorar durante a viagem ou logo depois, e, a memorabilidade porque o casal compartilhou os momentos que posteriormente foram divididos com os amigos ou entre o próprio casal.

É um nível de responsabilidade e comprometimento diferente... foi uma forma que a gente teve de se conhecer mais, coisas que descobrimos um do outro, tivemos discussões lá também sobre algumas coisas que a gente não concordava e eu acho que de uma forma geral foi uma maneira 
que a gente teve de amadurecer o nosso relacionamento. (C3)

A gente compartilhava uma cozinha, e tinha que lavar roupas juntos, limpar o quarto, limpar o banheiro, então foi bem uma amostra do possível futuro. Eu também colocava o P. pra frente 'vamos lá, vamos fazer, vamos sair'. A J. chegou lá e era meio bagunceira e eu meio sistemático. Mas ela saiu de lá mais organizada e eu mais animado. (C7)

Além disso, a viagem permitiu a formação e fortalecimento da confiança entre os parceiros(as). Isto é, há indícios de que a viagem tem como output a geração de vínculo a ponto de aumentar a confiança entre as partes do casal. A confiança é um aspecto que não foi demonstrado em pesquisas anteriores e, portanto, é uma contribuição deste estudo.

... eu fiquei mais confiante no P., porque querendo ou não ele quis me tirar da minha zona de conforto, né, porque eu não gosto de praia, não gosto de mar e 'não, você vai sim, você vai aprender a nadar e tal', e acho que pra confiança um no outro, pelo menos pra mim, foi muito importante pra isso. (C10)

... me sinto seguro com a J., o que não é comum, eu fico sempre inseguro, mas com ela eu tenho confiança, sei que ela vai estar comigo e isso é importante pra mim, aí eu aproveito mais as coisas, tenho liberdade para fazer outras coisas. (C7)

Por outro lado houve casais que relataram que a viagem permite uma maior aproximação do casal quando estes não estão juntos diariamente ou se conhecem bem. Todavia nos casos em que o casal está muito próximo, há relatos de que a viagem não afeta significativamente o relacionamento.

Próximos a gente já é muito. É, a intimidade já tinha muito. Era muito tranquilo, muito prático, sabe. (C11)

... a viagem é interessante para unir casais como um todo nos sentido de que você passa mais tempo juntos, sabe? Mas se você já passa muito tempo juntos, acaba que é um diferente só de lugar... mas em questão de conhecimento e tal, só traz mais impacto quando você não passa muito tempo com a pessoa... (C9)

Os entrevistados também relataram que por terem viajado juntos surgiu ou aumentou o desejo de viajarem juntos sempre que possível. Além disso, por estarem sempre viajando, casais acabam se tornando uma referência para os amigos que os procuram pedindo dicas, sugestões e os convidando para viajar.

Sim, e sei lá, a gente começou a ter esse pensamento, essa filosofia de sempre querer viajar. Sempre que for possível, tentar viajar, coisa que a gente não tinha muito antes dessa viagem. (C2)

... acaba também que para o nosso círculo de amizade a gente acaba se tornando referência, as pessoas sempre perguntam a gente dicas, convida a gente pra ir junto também... (C8)

Ademais, os sentimentos descritos pelos casais ao viajarem juntos costumam ser sempre positivos, como, felicidade, prazer, completude, amor, satisfação, alegria e confiança. 


\section{DISCUSSÕES}

Esse estudo aprofundou nos aspectos que tornam as viagens de casais específicas e o que as diferencia de outras viagens que foram feitas com amigos, com a família ou sozinho(a). Os casais apontaram que as viagens a dois permite a liberdade de se tomar as próprias decisões sobre passeios a fazer, local de hospedagem, data de viagem e horário das atividades, já que esses aspectos são decididos apenas pelo casal. Por outro lado, viagens em grupo ou com a família demanda a tomada de decisões em conjunto e nem sempre há consenso. Em comparação com uma viagem feita sem o parceiro(a), os entrevistados relataram que em viagens desacompanhados é comum surgir o desejo de compartiIhar aquele momento especial com o parceiro(a) ou imaginar como seria o momento se o parceiro (a) estivesse junto.

A figura 5 apresenta os aspectos que motivam as viagens, que a tornam memorável e que interferem no relacionamento.

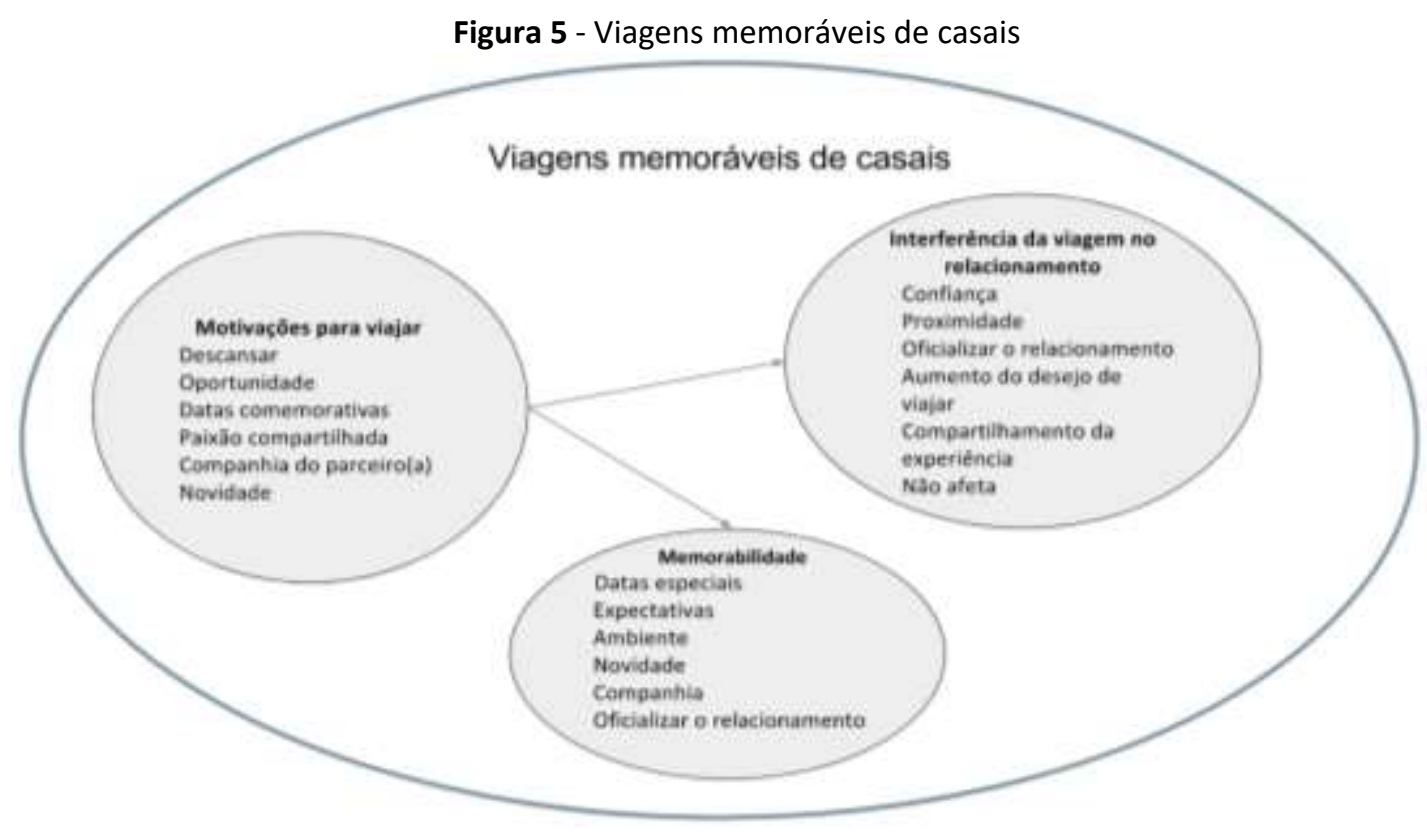

Fonte: Autoria própria

Outra diferença entre as viagens de casais e as demais reside em vivenciar a dois os momentos marcantes da viagem, o que, consequentemente, proporciona a vivência de estórias e de momentos que podem ser compartilhados posteriormente, ou entre o casal ou com os amigos, familiares e conhecidos.
As motivações para as viagens de casais e viagens com a família, amigos ou sozinho (a) também são diferente. Viagens de casais abarcam o desejo de passar um tempo juntos, aproveitando a companhia do outro (a), conversando, se conhecendo e fazendo atividades que os dois gostam. O planejamento da viagem de casal também é diferen- 
te de viagens com outras pessoas já que na primeira, o planejamento é feito por e para duas pessoas. Então, os locais visitados costumam ser locais românticos ou de interesse compartilhado. Eventualmente, o local a ser visitado pode ser de interesse de apenas uma das partes do casal, mas há um entendimento de que aquele local é um desejo de uma das partes e o outro quer contribuir para a realização desse desejo. Os locais ou tipos de refeições também são diferentes e a reserva do quarto ou meio de hospedagem é específica para o casal.

Entre as motivações para as viagens de casais relatadas no estudo estão: a novidade, o descanso, a data comemorativa, a oportunidade de viajar junto em uma data possível para ambos, a paixão em comum e a companhia. Os casais relataram a necessidade de fugir da rotina, diminuir o estresse, estar longe das preocupações e trazer para o relacionamento uma sensação de renovação. Pesquisas anteriores já haviam apontado o descanso, a sensação de renovação e a paz como aspectos importantes para que o turista tenha uma experiência memorável (Trauer \& Ryan, 2005; Kim, Ritchie \& McCormick, 2012; Kim \& Ritchie, 2014).

Sobre a interferência da viagem no relacionamento, os participantes relataram que a viagem afetou o relacionamento porque eles se tornaram mais próximos, oficializaram o relacionamento, fortaleceram a confiança entre os parceiros e compartilharam memórias. Houve, ainda, casais que relataram que a viagem não afetou o relacionamento. Além disso, houve um relato de como a viagem a dois fortaleceu o desejo de viajar.

Sobre a memorabilidade das viagens de casais, aspectos como datas comemorati- vas, novidades, ambiente visitado, a companhia, a oficialização do relacionamento e as expectativas que possuíam em relação à viagem contribuíram para tornar uma viagem determinada especial, em relação a outras sem uma das partes do casal. As paixões em comum dos casais que motivaram as viagens envolvem a história, culinária, artes, cultura e o micro negócio de viagem. Exemplos de paixões em comum que motivaram as viagens foram o time de futebol pelo qual o casal torce, as simulações temáticas em eventos específicos sobre isso. As datas comemorativas também podem ser consideradas tanto um motivador quanto um aspecto de memorabilidade das viagens de casais. Ambos paixão em comum e datas comemorativas são aspectos pouco explorados em estudos anteriores, tratando-se, portanto, de contribuições deste estudo.

Outra contribuição da pesquisa diz respeito à interferência da viagem no relacionamento, isto é, o aspecto da confiança. A viagem formou ou fortaleceu o vínculo da confiança entre os parceiros (as). Ademais, a viagem, por vezes, reafirma a escolha do parceiro (a). Outros resultados da interferência da viagem no relacionamento apontados pelos participantes são o aumento da intimidade, o compartilhamento das memórias da viagem e a oficialização do relacionamento (que também é um fator que interfere na memorabilidade da viagem). Tung e Ritchie (2011) já haviam apontado o desenvolvimento do relacionamento com o parceiro (a) e o aumento da intimidade como o ponto central da experiência memorável de viagens de casais, o que também é ressaltado nessa pesquisa.

O aspecto da novidade, que se refere 
a conhecer novos lugares, novas culturas e viver novas experiências corrobora estudos anteriores que afirmam que a experiência é o principal produto do mercado de turismo. $\mathrm{Ou}$ seja, experiências únicas se relacionam com a satisfação do turista e a experiência inédita é fixada na memória do mesmo. (Tsaur, Chiu, \& Wuang, 2007; Song et al., 2014; Pezzi \& Vianna, 2015).

$\mathrm{O}$ ambiente foi um fator de memorabilidade retratado em aspectos como as belezas naturais do local (deserto, vulcões, praias); estabelecimentos frequentados como bares e restaurantes; e o clima do local. Pezzi e Vianna (2015) já haviam destacado a dimensão estética, especialmente a arquitetura e belezas naturais, como uma dimensão fundamental para tornar uma viagem memorável.

Essa pesquisa demonstrou que independente de orientação sexual, idade ou tempo de relacionamento os casais possuem diversas características em comum, tais quais a motivação de viagem pautadas em datas comemorativas e paixões de uma ou ambas as partes do casal.

\section{CONSIDERAÇÕES FINAIS}

A pergunta que norteia este trabalho é: Qual a essência da experiência de casais de brasileiros que viajam a lazer? Assim, para alcançar o objetivo proposto, foram realizados 3 estudos diferentes que abordassem perspectivas diferentes e complementares. $O$ estudo 1 foi composto por 2 relatos de viagem executados pelo casal durante a viagem. $O$ estudo 2 foi composto por 13 narrativas, feitas após a viagem, mas que possibilitou apenas a visão de uma das partes do casal. O estudo 3 é composto por 11 entrevistas em profundidade com casais, ou seja, 22 pessoas de diferentes idades, gênero e orientação sexual, foram entrevistadas. A intenção do estudo em nenhum momento foi comparar ou segregar casais de orientações sexuais distintas. Pelo contrário, o estudo contribui para demonstrar que independente do tipo de orientação sexual, idade e status de relacionamento, há características comuns que caracterizam a viagem a dois.

Essa pesquisa avança ao abordar viagens de lazer em casais, visto que existem poucos estudos específicos da viagem a dois que abordam aspectos como a paixão e interesse em comum; o planejamento de viagem específico para viagem a dois; e o aspecto da confiança que não foi abordado em pesquisas anteriores de experiência turística e que diversos casais relatam como uma consequência da viagem. Assim, por vezes, a viagem a dois reforça a decisão do casal de estarem juntos e aumenta a confiança no parceiro(a), bem como cria momentos e experiências de vida que podem ser compartilhadas entre o casal e/ou amigos, conhecidos e familiares.

Os resultados da pesquisa demonstram que organizações de destino turístico, como agências de viagens, agência de turismo receptivo, restaurantes, hotéis e outros, devem identificar paixões em comum do casal. Além disso, investir em pacotes e serviços especiais para a comemoração de 
datas como aniversário de namoro e de casamento pode influenciar positivamente o consumo e a memorabilidade da experiência dos casais. Isso pode contribuir para a prestação de serviços que gerem momentos distintos e marcantes para o casal, contribuindo para a recomendação e a intenção de revisitar (Triantafillidou \& Petala, 2015; Tung \& Ritchie, 2011; Tsaur et al., 2007).

Dentre as limitações teóricas da pesquisa, está o fato dos casais serem o enfoque da pesquisa, ao passo que a teoria de experiência turística foi enfatizada até então, sob aspectos individuais, influenciada por aspectos físicos e sociais. Pesquisas futuras podem, por exemplo, contribuir para entender viagens a dois de casais em relação ao ciclo de vida familiar.

Outra limitação metodológica da investigação está o fato dos participantes poderem adicionar elementos e situações ficcionais à narrativa. Ademais, é difícil a conjugação de todos os elementos passíveis de análise. Por isso, é recomendado que a narrativa seja conjugada a outras formas de investigação qualitativa (Matos et al., 2005). Além disso, o fato da pesquisa qualitativa não ser neutra também pode ter causado vieses não intencionais durante o manuseio e coleta do material.

Uma sugestão para pesquisas futuras é abordar a intimidade e relações sexuais entre os casais durante a viagem, já que este foi um aspecto que não foi diretamente exposto pelos casais durante os estudos ainda que tenha emergido de forma implícita em algumas questões da entrevista. Alguns pontos que podem ter inibido os casais de abordarem a intimidade sexual de forma explícita nas entrevistas, são: o casal não ter se sentido à vontade para discutir esse tema com a entrevistadora, o casal não discutir abertamente sobre isso ou não querer expor o parceiro, já que estavam juntos nas entrevistas ou ainda, porque a intimidade sexual não foi diretamente abordada. Ademais, estudos de casais de outras faixas etárias e casados por tempos variados podem ser interesse de estudos futuros.

\section{AGRADECIMENTOS}

Agradecemos aos envolvidos no estudo, em especial os participantes dos três estudos e a Pró Reitoria de Graduação da UFMG, que arcou com uma bolsa de pesquisa para a condução do projeto.

\section{REFERÊNCIAS}

Arnould, E. J., \& Price, L. L. (1993). River Magic: Extraordinary Experience and the Extended Service Encounter. Journal of Consumer Research, 20(1), 24.

Beni, M. C. (2004). Turismo: da economia de serviços à economia da experiência. Turismo Visão $e$ Ação, 6(3), 295-306.

Bardin, L. (2008). Análise de conteúdo. Edições 70, Lisboa.

Bharwani, S., \& Jauhari, V. (2013). An exploratory study of competencies required to co-create memorable customer experiences in the hospitality industry. International Journal of Contemporary Hospitality Management, 25(6), 823-843.

Brasil. (2009). Pesquisa Hábitos de Consumo do Turismo do Brasileiro. Brasília: Ministério do Turismo.

Campos, A. C., Mendes, J., Valle, P. O. do, \& Scott, N. (2016). Co-Creation Experiences: Attention 
and Memorability. Journal of Travel \& Tourism Marketing, 33(9).

Carù, A., \& Cova, B. (2003). Revisiting Consumption Experience: A More Humble but Complete View of the Concept. Mark. Theory 3, 267-286. doi:10.1177/14705931030032004.

Cohen, E. (1979). A Phenomenology of Tourist Experiences. Sociology 13, 179-201.

Gama, G. L. G., \& Siqueira, E. D. de, (2010). "Viagens de Sonho": Considerações Teóricas sobre a Lua-de-mel. VI Seminário de Pesquisa em Turismo do Mercosul- Semintur. Anais...Caxias do Sul.

Hannam, K. (2004). Tourism and Development II: marketing destinations, experiences and crises. Prog. Dev. Stud. 4, 256-263.

Kim, J-H. (2010). Determining the Factors Affecting the Memorable Nature of Travel Experiences. Journal of Travel \& Tourism Marketing, 27(8), 780-796.

Kim, J-H., Ritchie, J. R. B., \& McCormick, B. (2012). Development of a Scale to Measure Memorable Tourism Experiences. Journal of Travel Research, 51(1), 12-25.

Kim, J., \& Ritchie, J. (2014). Cross-Cultural Validation of a Memorable Tourism Experience Scale (MTES). Journal of Travel Research, 53(3), 323335.

Knobloch, U., Robertson, K. \& Aitken, R. (2014). (Mis) Understanding the Nature of Tourist Experiences. Tourism Analysis, 19, 599-608.

Komppula, R., Ilves, R., \& Airey, D. (2016). Social holidays as a tourist experience in Finland. Tour. Manag. 52, 521-532.

Lawson, R. (2010). Consumer Behaviour. In: Baker, M., \& Saren, M. (Eds.). Marketing Theory: A Student Text. 2. ed. London: SAGE.
Malhotra, N. K. (2004). Pesquisa de Marketing: Uma Orientação Aplicada. Porto Alegre: Bookman.

Matos, A., Branco, N., \& Barradas, F. (2005). Investigação Narrativa.

Oh, H., Fiore, A. M., \& Jeoung, M. (2007). Measuring Experience Economy Concepts: Tourism Applications. Journal of Travel Research, 46(2), 119-132.

Pearce, P. L., \& Wu, M.-Y. (2014). Tourists' Evaluation of a Romantic Themed Attraction: Expressive and Instrumental Issues. Journal of Travel Research, 19, 1-13.

Pezzi, E.; Vianna, S. L. G. (2015) A Experiência Turística e o Turismo de Experiência: um estudo sobre as dimensões da experiência memorável. Turismo em Análise, 26(1).

Pine, J. B., \& Gilmore, J. B. (1999). The Experience Economy: Work is Theatre \& Every Business a Stage. Boston, MA: Harvard Business School Press.

Quinlan-Cutler, S., \& Carmichael, B. (2010). The Dimensions of Customer Experience. In: Morgan, M., Lugosi, P., \& Ritchie, B. (Ed.). The Tourism in Leisure Experience: Consumer and Managerial Perspectives. Bristol: Aspects of Tourism, 3-26.

Riessman, C. K. (2005). Narrative Analysis. In: Kelly, N. et al. (Eds.). Narrative, Memory and Everyday Life. Huddersfield: University of Huddersfield, 1-7.

Schmitt, B. (2000). Marketing Experimental. São Paulo: Nobel.

Song, H. J., Lee, C.-K., Park, J.-A., Hwang, Y.-H., \& Reisinger, Y. (2014). The Influence of Tourist Experience on Perceived Value and Satisfaction with Temple Stays: The Experience Economy Theory. Journal of Travel \& Tourism Marketing. 
Trauer, B., \& Ryan, C. (2005). Destination Image, Romance and Place Experience: An Application of Intimacy Theory in Tourism. Tourism Management, 26, 481-491.

Triantafillidou, A. \& Petala, Z. (2015). The Role of Sea-Based Adventure Experiences In Tourists' Satisfaction and Behavioral Intentions. Journal of Travel \& Tourism Marketing, v. 8408, n. November, p. 1-21.

Trigo, L. G. G. (2010). A viagem como experiência significativa, In: Panosso Netto, A., Gaeta, C. (Eds.), Turismo de Experiência. Editora Senac São Paulo, São Paulo, 21-41.

Tsaur, S-H., Chiu, Y-T., \& Wang, C-H. (2007). The Visitors Behavioral Consequences of Experiential Marketing: An Empirical Study on Taipei Zoo. Journal of Travel \& Tourism Marketing, 21(1), 4764.

Tung, V. W. S., \& Ritchie, J. R. B. (2011). Investigating the Memorable Experiences of the Senior Travel Market: An Examination of the Reminiscence Bump. Journal of Travel \& Tourism Marketing, 28(3), 331-343.

Tussyadiah, I. P., \& Fesenmaier, D. R. (2009). Mediating Tourist Experiences. Access to Places via Shared Videos. Annals of Tourism Research, 36(1), 24-40.

Uriely, N. (2005). The tourist experience: Conceptual developments. Annals of Tourism Research, 32(1), 199-216.

Vieira, V. A., \& Tibola, F. (2005). Pesquisa Qualitativa em Marketing e suas Variações: Trilhas para Pesquisas Futuras. Revista de Administração Contemporânea, 9(2), 9-33.
Walls, A. R. (2013). A cross-sectional examination of hotel consumer experience and relative effects on consumer values. Int. J. Hosp. Manag. 32, 179-192. doi:10.1016/j.ijhm.2012.04.009

\section{Informações dos Autores}

\section{Mariana de Freitas Coelho}

Doutora e Mestre em Administração (UFMG). Pós-graduada em Gestão de Projetos (UFMG) e graduada em Turismo (UFMG). Atualmente é professora do curso de Administração da Faculdade Batista de Minas Gerais. Atuou em diversas instituições de ensino superior e tecnológico desenvolvendo ações de Docência, Pesquisa e Extensão. E-mail: marifcoelho@gmail.com. ORCID: https://orcid.org/0000-0002-7081-1429.

\section{Kelly Cristine de Oliveira Meira}

Graduada em Relações Econômicas Internacional pela Universidade Federal de Minas Gerais. Atuou por três anos como bolsista do Núcleo de Estudos e Estratégias de Comunicação Integrada de Marketing e Turismo (Neecim- Tur). E-mail: kellycristineomeira@gmail.com. ORCID: https://orcid.org/00000002-8666-6107

\section{Marlusa de Sevilha Gosling}

Possui graduação em Ciência da Computação pela Universidade Federal de Minas Gerais (1992), mestrado em Administração pela UFMG (2001) e doutorado em Administração pela UFMG (2004) e pós doc em Gestão do Turismo na Universidade de Algarve (2015). Atualmente é professora Associada de Marketing da Universidade Federal de Minas Gerais, Coordenadora do NEECIM-TUR (Núcleo de Estudos e Estratégias em Comunicação Integrada de Marketing e Turismo) e Coordenadora da Pós-Graduação Lato Sensu do CEPEAD/FACE/UFMG, curso de Gestão Estratégia. Além disso, é Editora-chefe do periódico Marketing \& Tourism Review. E-mail: mg.ufmg@gmail.com. ORCID: https://orcid.org/0000-0002-7674-2866 . 